\title{
Correction to: Contrasting transcriptional responses of PYR1/PYL/RCAR ABA receptors to $A B A$ or dehydration stress between maize seedling leaves and roots
}

Wenqiang Fan, Mengyao Zhao, Suxin Li, Xue Bai, Jia Li, Haowei Meng and Zixin Mu*

\section{Correction}

Following publication of the original article [1], a reader spotted that the article appears to have some misplaced/ duplicated figures. In particular, Fig. 5a and Fig. $6 \mathrm{a}$ appear to be identical, and do not match what is written in the text. The authors apologized for this oversight and supplied the original pictures, which are reproduced below.

Received: 9 April 2018 Accepted: 9 April 2018

Published online: 30 April 2018

\section{Reference}

1. Fan W, Zhao M, Li S, Bai X, Li J, Meng H, Mu Z. Contrasting transcriptional responses of PYR1/PYL/RCAR ABA receptors to ABA or dehydration stress between maize seedling leaves and roots. BMC Plant Biology. 2016;16:99. https://doi.org/10.1186/s12870-016-0764-x.

* Correspondence: muzx@nwsuaf.edu.cn

College of Life Sciences, Northwest A\&F University, Yangling 712100, Shaanxi, China 

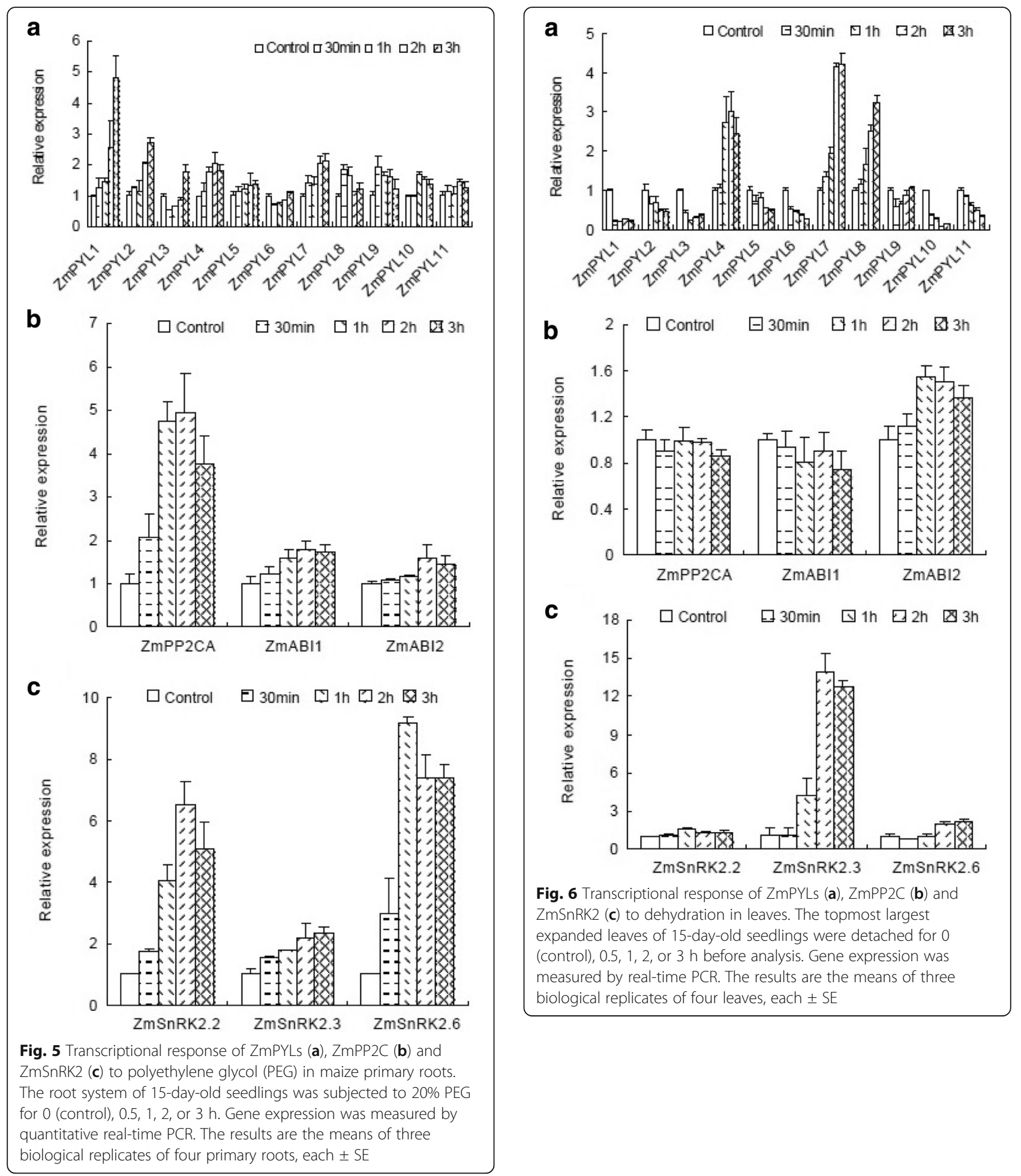